Guidance for Substance-Related Environmental Monitoring Strategies Regarding Soil and Surface Water

In environmental polices, substance-related monitoring is an essential tool for risk assessment. The soundness of policy decisions, including risk management measurers, are directly related to the reliability of the environmental monitoring programs. In addition, monitoring programs are needed for identifying new and less-investigated pollutants of concern in different environmental media.

Scientifically sound and feasible monitoring concepts strongly depend on the aim of the study. The proper definition of questions to be answered is of pivotal importance. Therefore, this new IUPAC project will address different approaches to substance-related monitoring for soils and surface water, including sediment.

The project objectives are as follows:

- provide guidance for the selection, elaboration, and performance of substance-related monitoring strategies regarding soil and surface water sampling

- provide an overview of available, scientifically sound and feasible monitoring strategies for substance-related environmental monitoring

- discuss advantages and shortcomings of different strategies, requirements for technical and personal equipment, and quality assurance

The aim of investigative monitoring or "snapshot monitoring" is to get a first impression of the pollution of selected areas or input scenarios (e.g., monitoring of inputs via sewage sludges within a certain region) and to screen for new and less investigated pollutants of environmental concern. This investigative monitoring often does not fulfill the criteria for being "representative" since it does not involve systematic selection of sampling sites for sheer pragmatic reasons.
Trend monitoring and compliance monitoring operate within well-selected sampling sites. The aim of this study type is to accurately trace the concentrations over a certain time period, thus allowing detection of seasonal variations, accidental inputs, and the effectiveness of regulations.

Storage of samples and repeated sampling at wellselected and carefully documented sites can lead to retrospective monitoring as performed by environmental specimen banks. In this context, the proper documentation of related meta-data is paramount to explain and interpret the observations on the "timecapsuled" samples. Sample handling, storage, and the analysis of the samples are important steps.

For more information and comments, contact Task Group Chair Werner Kördel <koerdel@ime.fraunhofer.de〉.

iii. www.iupac.org/web/ins/2009-048-1-600

\section{Evaluated Kinetic Data for Atmospheric Chemistry}

The Subcommittee on Gas Kinetic Data Evaluation for Atmospheric Chemistry is providing critically reviewed recommended kinetic and mechanistic data for reactions important in the atmosphere. These data may be incorporated into the next generation of climate and air quality models which describe chemical processes occurring on local, regional, and global scales and which will guide policy development. Data such as these form the backbone of any predictive numerical simulations of the global climate upon which potentially far-reaching political decisions are based.

This project will support the continuous updating of the web-based database <www.iupac-kinetic. ch.cam.ac.uk> on atmospheric reactions located at the Centre for Atmospheric Science in the Department of Chemistry, University of Cambridge, UK. The migration to the web was begun in 2001 (IUPAC project 1999037-2-100) and was essentially concluded in 2008 at the end of project 2007-001-2-100. The website contains approximately 1000 data sheets covering gas phase reactions, photolysis reactions, and heterogeneous reactions on liquids and on solids. Parallel to the ongoing updating, completing, and reevaluation of the web-based data, "snapshots" of certain parts of the database are published in a series of peer-reviewed articles in Atmospheric Chemistry and Physics. ${ }^{1-5}$ 
It is clear that this effort should continue in view of the considerable scientific activity in this field and the new results it generates. The subcommittee is currently expanding the existing database to consider new gas phase data sheets and recommendations for selected complex hydrocarbon reactions, including aromatic species and haloalkanes and new data sheets for heterogeneous reactions on ice, mineral dust, liquid water, and sulfuric acid surfaces.

\section{References}

1 R. Atkinson, et al., Evaluated kinetic and photochemical data for atmospheric chemistry: Volume I-gas phase reactions of $\mathrm{O}_{x}, \mathrm{HO}_{x}, \mathrm{NO}_{x}$, and $\mathrm{SO}_{x}$ species, Atmos. Chem. Phys., 4, 1461-1738 (2004).

2 R. Atkinson, et al., Evaluated kinetic and photochemical data for atmospheric chemistry: Volume II-gas phase reactions of organic species, Atmos. Chem. Phys., 6, 3625-4055 (2006).

3. R. Atkinson, et al., Evaluated kinetic and photochemical data for atmospheric chemistry: Volume III-gas phase reactions of inorganic halogens, Atmos. Chem. Phys., 7, 981-1191 (2007).
4. R. Atkinson, et al., and T. J. Wallington, Evaluated Kinetic and Photochemical data for Atmospheric Chemistry: Volume IV-Gas Phase Reactions of Organic Halogen Species, Atmos. Chem. Phys., 8, 4141-4496 (2008).

5. J. N. Crowley, et al., Evaluated Kinetic and Photochemical data for Atmospheric Chemistry: Volume $\mathrm{V}$-heterogeneous reactions on solid substrates, Atmos. Chem. Phys., in press.

For more information and comments, contact Task Group Chair Tim J. Wallington <twalling@ford.com>.

\section{Cin. www.iupac.org/web/ins/2009-031-1-100}

In early 2010, the IUPAC Subcommittee for Gas Kinetic Data Evaluation began using an RSS feed for its website.

\section{(1iil www.iupac-kinetic.ch.cam.ac.uk/feed/}

For those unfamiliar with RSS feeds, Glenn Carver suggests a useful description provided by the BBC: http://news.bbc. co.uk/1/hi/help/3223484.stm

\section{Provisional Recommendations}

Provisional Recommendations are drafts of IUPAC recommendations on terminology, nomenclature, and symbols made widely available to allow interested parties to comment before the recommendations are finally revised and published in Pure and Applied Chemistry. Full text is available online.

\section{Glossary of Terms Used in Photocatalysis and Radiocatalysis}

This glossary of terms covers phenomena considered under the very wide terms "photocatalysis" and "radiocatalysis" or "radiation catalysis." A clear distinction is made between phenomena related to either photochemistry and photocatalysis or radiation chemistry and radiocatalysis. Consistent definitions are given of terms in these areas, as well as definitions of the most important parameters used for the quantitative description of these phenomena. Terms related to the up-scaling of photocatalytic processes for industrial applications have been included. This
Glossary should be used together with the "Glossary of Terms used in Photochemistry," 3rd version, IUPAC Recommendations 2006: as well as with the IUPAC Compendium of Chemical Terminology, 2nd edition (the "Gold Book") because many terms used in photocatalysis are defined in these documents.

\section{Comments by 31 July 2010}

Prof. S.E. Braslavsky

<braslavskys@mpi-muelheim.mpg.de>

Max-Plank-Institut für Bioinorganische Chemie Mülheim/Ruhr, Germany

Sim. www.iupac.org/web/ins/2001-036-1-300 